\title{
Modeling macroeconomic indicators in unstable economies
}

\author{
Yuliia Zhukova \\ Finance and Economics Department, \\ Borys Grinchenko Kyiv University, \\ Ukraine \\ y.zbukova@,kubg.edu.ua \\ ORCID 0000-0001-6312-9600 \\ Olena Sobolieva-Tereshchenko \\ Finance and Economics Department, \\ Borys Grinchenko Kyiv University, \\ Ukraine \\ t8000@i.ua \\ ORCID 0000-0002-1086-1192
}

Abstract. A method for analysis of the dynamics of macroeconomic indicators based on the model of a piecewise trend for economies of unstable growth is proposed. The relevance of the article is supported by the absence of adequate mathematical models and the inadequacy of traditional continuous models to describe the features of economic dynamics of this type. Its application is demonstrated on the examples of Ukraine, Greece and Italy in comparison with stable developing countries of Eastern Europe - the Czech Republic, Slovakia and Poland. In the process of approbation new indices of instability based on

Received: June, 2020

1st Revision: April, 2021 Accepted: May, 2021

DOI:

$10.14254 / 2071$ $8330.2021 / 14-2 / 9$ this model have been developed. A higher degree of conformity of the proposed model is proved in comparison with traditional continuous models not only for countries with signs of unstable economic dynamics, but also for some countries with stable economies. During approbation, a new index of instability of growth was developed based on this piecewise linear trend model. The indices of instability of growth were calculated for 43 European countries for the period from 1989 to 2019 and their rating was built.

Keywords: GDP per capita, piecewise model, small squares method, growth instability index, Czech Republic, Slovakia, Poland, Ukraine, Greece, Italy.

JEL Classification: E27, D61, G17 


\section{INTRODUCTION}

Mathematical modeling of the dynamics of macroeconomic indicators belongs to the number of the most important tools for analysis of economic development trends. Its purpose is, in particular, to help work out proposals for management solutions. The IMF research department heads Andrew J. Berg. and Jonathan Ostrey noticed that “... a key feature of the growth process in developing countries - lack of stability ... periods of rapid growth are interchanged with periods of decline and stagnation - ups, downs and stable periods of growth" (Berg \& Ostry, 2011).

The unstable growth is characterized by the time trend of the economic indicator which is experiencing gaps caused by sharp economic changes. Capabilities of the small squares method, usually used for analysis, are limited to the choice of functions of regression (trend). The latter is conditioned by the necessity of reducing the problem of finding the estimates of parameters to the solution of a system of linear equations. That is why the popular computer applications use linear, exponential, polynomial, power-degree or logarithmic trends. Their common properties are smoothness and continuity.

For countries with unstable growth traditional regression analysis is not effective. Real data indicates that periods of stable growth are replaced by gaps in continuous trend. Thus, the problem of simulation of the dynamics of unstable economies acquires relevance. This purpose is stated by the authors in this article.

One of the features of continuous models is that the parameters of the trend equation (coefficients of polinome, exponent parameters, etc.) do not, as a rule, have an economic content. The authors propose a model of piecewise dynamics and the technology of its implementation using the example of the indicator of GDP per capita. It is not only more accurate in describing specific features of unstable growth dynamics, but it has one more advantage: its parameters have natural economic content that makes accessible and transparent their interpretation. These parameters are the moments of drastic change in dynamics (gaps) and coefficients of linear components characterizing the rates of growth in the intervals of stability. As the review has showed, the proposed model is used for the first time in the form ready for practical implementation of the method.

For the demonstration of the method and comparative analysis the Czech Republic, Slovakia, Poland, Greece, Italy and Ukraine have been chosen. In the proposed model not only the result of the estimate of the dynamics of the indicator is provided but also its derivative, which illustrates the pace of the performance of the indicator which also undergoes a break.

The goal of the authors was also to develop a generalized indicator, a quantitative characteristic of the features of the degree of instability of growth, called by the authors the "growth instability index", and to construct a rating of European countries on the basis of this indicator.

The hypotheses laid as the basis of the study include:

- unstable growth is characterized by a gap in the trend that prevents the implementation of a continuous and smooth model from being applied;

- for an integrated display of unstable growth experiencing breaks, it is possible to apply piece-continuous functions, in particular, piecewise function;

- instability of growth can be estimated quantitatively using the index that takes into account amplitudes of vibrations; growth stability will be characterized by low index values, instability - by high ones;

- piecewise trend will be able to reveal the presence or absence of cyclicity in the manifestations of instability of growth;

- analysis conducted with the use of the model for different countries will allow to detect exogenic and endogenic factors of unstable growth. 
The hypotheses should include the expected prospects of this model in a multidimensional design, that is, using not a single one, but a set of indicators characterizing the instability factors identified at the stage of analyzing the dynamics gaps when using a one-dimensional piecewise linear model.

\section{LITERATURE REVIEW}

The GDP indicators are regularly published by statistical departments of various countries and international organizations (UNdata, 2021; Eurostat, 2021; World Bank, 2021).

Based on the analyses of the dynamics of GDP and its components, the patterns of development and economy growth, cycles and resistance of different economies to them become apparent. Thus, (Baburin, 2019) researched the resilience of the economies of the Greater Baltic Region to the cycles `conditions, calculated the cycle duration of 5-7 years and indicated that the main factor of stability of a country is its specialization. In their works (Korotayev et al., 2020) studied Kondratiev's long waves based on growth rates of global GDP and concluded that it is the developing countries that are generating such waves during the given period.

(Göbel \& Araújo, 2020) went further. Their article is dedicated to identifying macroeconomic indicators - early warning signs of economic crises. And on this basis the clusterization method for changing policies and creating a more stable economy is proposed. This provides an opportunity to state that there are certain classes of countries resistant to external vibrations, while some others remain vulnerable. Their dynamics is not continuous, that is, it experiences the gaps.

The method of the small squares and its modifications is often applied for macroeconomic modelling of GDP dynamics, with the help of which the coefficients of the regression function reflecting the dynamics of the indicator are estimated. The group of researchers (Karaçuha et al., 2020) used the small squares method to forecast GDP per capita for the population of Brazil, China, India, Italy, Japan, the UK, the USA, Spain and Turkey. It has been shown that their proposed method is superior to the polinomial and fractional models.

Regressions are frequently used in analysis of relationship between main macro-indicators, in particular for estimating the factors of influence on economic growth for individual countries as well as regions: impact of human capital on the development of EU countries (Laskowska \& Dańska-Borsiak, 2017); public debt management of Italy and Greece (Zahariev et al., 2020); relationship between energy consumption and economic growth for 30 European countries (Stjepanović, 2018); assessment of the short-term impact of COVID-19 on economic activity (Fezzi \& Fanghella, 2020) and others.

Characteristic of the degree of conformity of the applied growth model with the retrospective data, on the basis of which it is obtained, is the multiple coefficient of correlation (correlation ratio), values of which are in the range [0..1]. Values correlation ratio of up to 0.5 is estimated as a low level of conformity, from 0.5 to 0.9 - low to medium, 0.9 to 0.99 - medium to high.

Traditional continuous models often provide high performance. In their article the authors (Xiaobo Zhu et al., 2017) used linear, square, polynomial and power-degree functions for analysis of connection between Gross Domestic Product (GDP) of China and Temporal Coverage Nighttime Light Data (TNL) at the national level and for separate provinces. They provided a fully acceptable result $\left(\mathrm{R}^{2}=0.95\right.$ and above). Possible trend gaps were not considered, for they were not there.

The article (Karnitis \& Karnitis, 2017) is devoted to modeling the stable growth of the economies of the EU and the Baltic states (Estonia, Latvia, Lithuania) using multidimensional linear regression, i.e. a continuous function. The reliability of the simulation result $\left(\mathrm{R}^{2}=0.9736\right)$ is high precisely due to the stable growth of the studied economies. 
In the article (Kasianova et al., 2020) the experience of analysis of economic dynamics is demonstrated on the basis of using the fourth degree polynome for description of the derivative - GDP growth rate of Ukraine. However, the polynomial model, being smooth, does not take into account the gaps of the dynamic's indicator, allowing to assess only the general direction of the trend. From the graphics in the article, it is quite evident. Critical periods of 2008-2009 and 2013-2014 are specified in the article as such when the function reaches the extreme and undergoes the trajectory changes.

The fact does not require the proof that the modelling problem is becoming much more complicated if the economy gets signs of unstable growth, to the specific features of which the article is dedicated (Berg \& Ostry, 2011).

The protracted crisis in the Greek economy has been widely discussed. The causes are studied (Chletsos \& Roupakias, 2020), economic growth is modeled by taking into account internal and external imbalances (Soukiazis et al., 2018). The factors of financial instability (Reyes Escobar \& Rozo Bernal, 2020) and the impact of the Greek crisis on Eurozone and non-Eurozone countries (Bird et al., 2017) are studied. The authors (Vlasova \& Govorova, 2018) analyze the dynamics of socio-economic development of Greece from 2008 to 2018 and the causes of the long-term crisis in institutional and economic aspects. From the above data, there is a significant increase in public debt $(1.63$ times) and a decline in GDP per capita by $44 \%$ over the period.

(Cicceri et al., 2020) provide data on the dynamics of inflation and unemployment in Italy for the period 1995 - 2019. The presented trends demonstrate that the dynamics have experienced sharp changes within short periods of time - from noticeable growth to the clearly expressed downfall, which is also one of the manifestations of unstable growth.

So, the application of continuous models for economies displaying signs of unstable growth is inefficient, which is obvious enough. The review of the literature has shown that the piecewise model has wide areas of application as a tool of applied research in physics, astronomy, computer sciences, materials science and engineering. Economic research is no exception. Such models are widely used in assessing the profitability of financial instruments and risk reduction (Tak KuenSiu, 2016; Coleman et al., 2007; Gawon Yoon, 2013). Applications in logistics (Basciftci et al., 2021) also show high efficiency. Macroeconomic issues, in which there are manifestations of sharp changes and gaps, are also solved through the use of piecewise linear functions. The article (Yi-Chein Chiang et al., 2008) demonstrates the possibilities of applying such models for assessing the effectiveness of foreign investment, (Matsuyama et al., 2018) as well as for the characterization and modeling of credit cycles.

The conducted literature review defined the choice of countries of unstable growth for the approbation of the piecewise linear function method, namely: Ukraine, Greece, Italy. For comparison, the data for Poland, the Czech Republic and Slovakia as the stable developing European countries was used.

Ukraine, in terms of the nature of its development, has become a striking antipode to successful European countries. According to the UN Human Development Index (HDI) global rating for 2018, no other European country ranks lower than Ukraine (UNdata, 2018).

At the same time, in 1989, per capita gross domestic product (GDP) value in Poland and Ukraine was at a comparable level (World Bank, 2019). In 26 years, their economies are widely apart. Foreign direct investment led to contrasting, in essence, results in relation to stability of growth and institutional changes (Kowalski \& Shachmurov, 2018). Similar studies have been conducted for the Greek economy (Baltas et al., 2018).

The Czech Republic, Slovakia and Poland as well as Ukraine, are rich in natural resources and minerals, which are similar in composition. Like Ukraine, they can also be considered as post-Soviet states, for the Czech Republic and Slovakia used to constitute a single state. The starting positions of all four states at the beginning of the 90s were almost identical: a significant share in the economic structure 
belonged to the machine building, coal industry, ferrous metallurgy, the chemical industry, military industry, developed nuclear energy (the Czech Republic, Slovakia, Ukraine) and agriculture (Poland and Ukraine).

Researches of Legatum Prosperity Index, BDO International Business Compass from 2008 to 2017 in Poland, Romania, Slovakia, in comparison with Ukraine, the above conclusions are also confirmed (Sobolieva-Tereshchenko, 2018). So, according to the BDO IBC, in 2017 such EU member states as Poland - 24th, Slovakia - 33rd and Romania - 36th, received the highest marks for their economic position. At the same time, Ukraine has the lowest indicator - the 80s. According to the Legatum Prosperity (LP) Index, in the period from 2008 to 2017, Ukraine had the lowest economic LP Index among countries; Poland had the highest LP Index. Also, research on stress testing of banks in Ukraine showed that banks with foreign capital from Eastern Europe and Central Asia, especially Hungary and Poland, are the most stress-resistant (Sobolieva-Tereshchenko \& Zhukova, 2020).

\section{METHODOLOGY}

The peculiar qualities of the economic dynamics of Ukraine are not limited to periods of deep but continuous decline. They are combined with sharp violations of continuity, which have not been observed on such a massive scale in the countries of stable development. It is this feature that creates the greatest difficulty in forecasting, since the applied analytical apparatus is designed to use continuous models. It prompted the authors to find the method for describing the dynamics of an indicator in a piecewisecontinuous, namely piecewise-linear model, for the time being in a one-dimensional version. As the first results have shown, the method appears to have promising prospects in the multidimensional version.

In Figure 1a the dots (Value) show the dynamics of per capita GDP at the PPPs (in permanent International dollars in 2011) for the period from 1990 to 2017 in Ukraine. The data is obtained from the (World Bank, 2019).

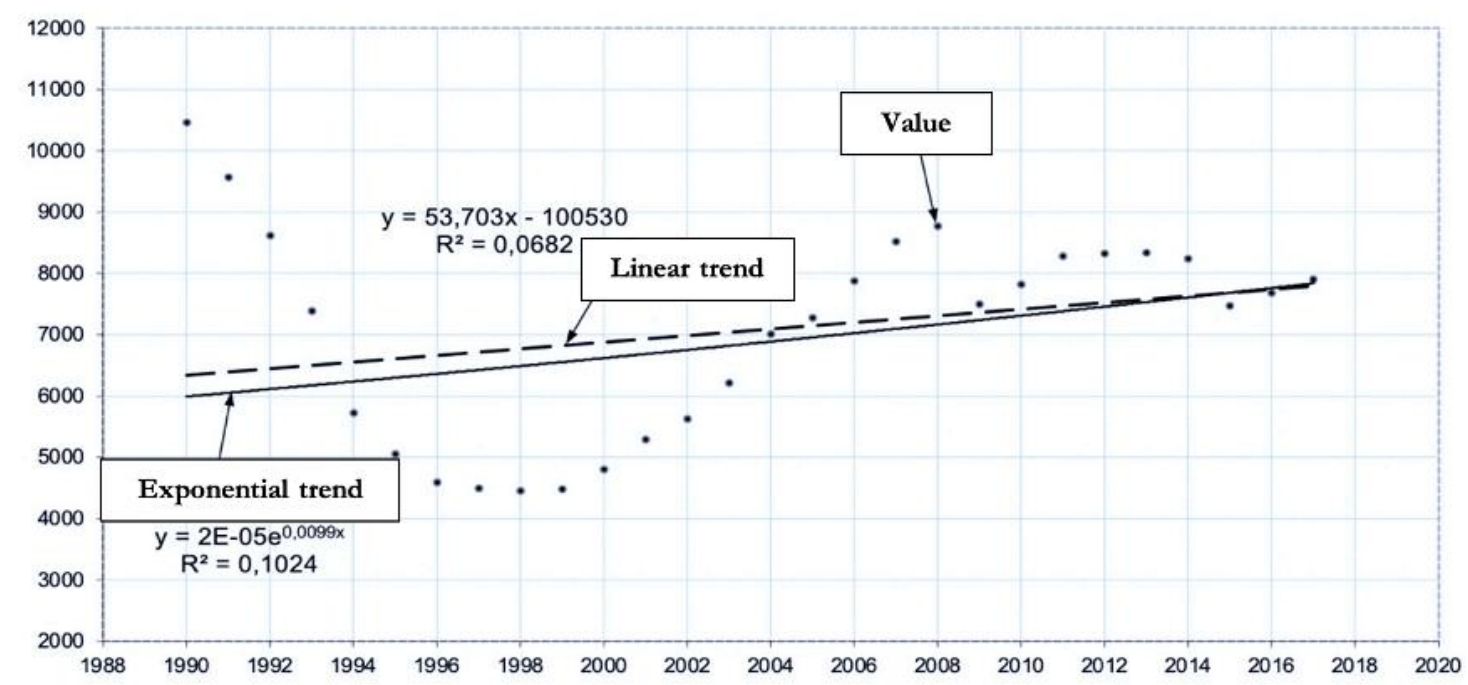

Figure 1a. Ukraine. The GDP performance per capita at the PPP (in permanent international dollars of 2011) for 1988 to 2018. The linear and exponential models

Source: own evaluation. 
It demonstrates the trend assessment for the linear, polynomial and exponential models and untenable character. The GDP performance per capita in 2017 is $75.5 \%$ of the 1990 value (decline of $24.5 \%)$.

Figure $1 \mathrm{a}$ and $1 \mathrm{~b}$ show the values of the indicator, referred to in Excel as "the value of the reliability of approximation $\mathrm{R}^{2}$ and representing the square of the correlation ratio. For a linear approximation $\mathrm{R}^{2}=$ $0.068(\mathrm{R}=0.26)$; exponential $-\mathrm{R}^{2}=0.1024(\mathrm{R}=0.26)$; polynomial of the 2 nd order $-\mathrm{R}^{2}=0.3257(\mathrm{R}=$ 0.57). Even polynomial of the 6th order, redundant for a relatively small base, shows unsatisfactory compliance in the area of manifestation of unstable development (starting with 2006) (Figure1b).

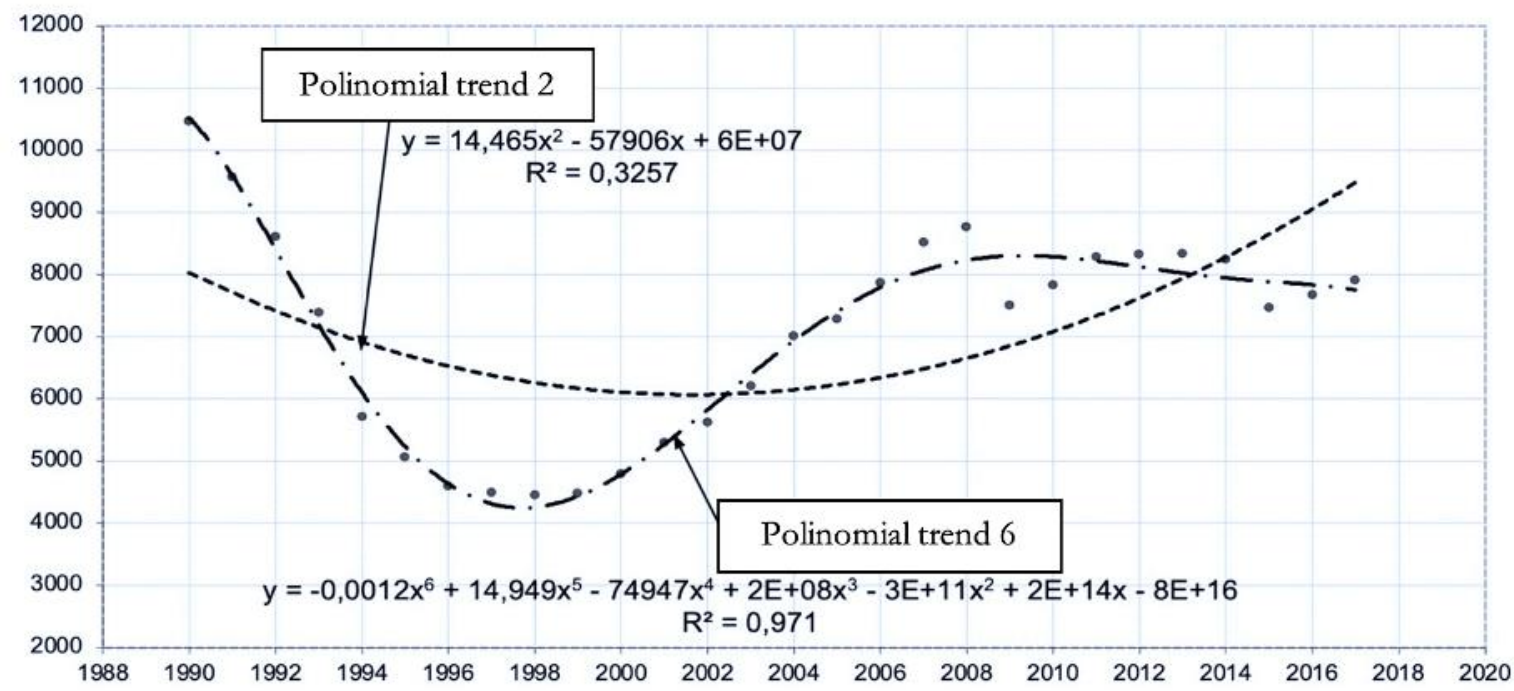

Figure 1b. Ukraine. The GDP performance per capita at the PPP (in permanent international dollars of 2011) for 1988 to 2018 . The polynomial model of the 2 nd and $6^{\text {th }}$ order

Source: own evaluation.

The failare of continuous models for forecasting dynamics of this nature, which has been observed in Ukraine since the `90s, is illustrated in Figure $2 \mathrm{a}$ and $2 \mathrm{~b}$.

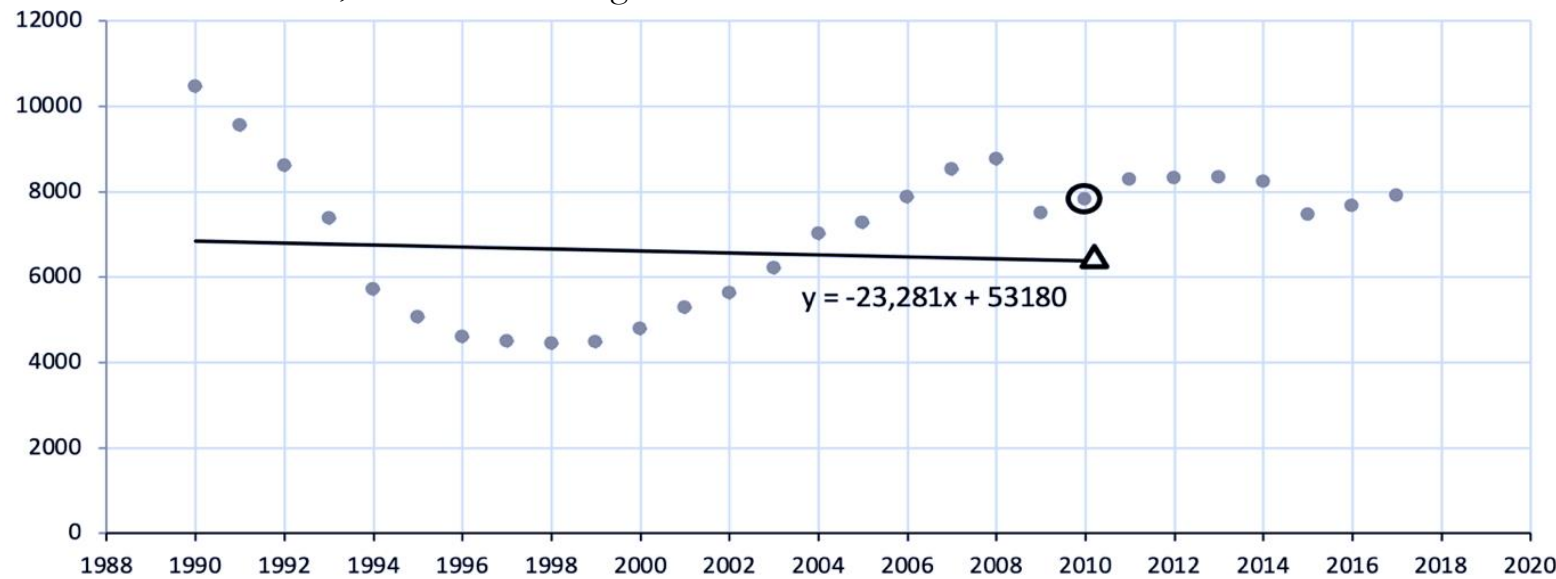

Figure 2a. Ukraine. The GDP performance per c apita at the PPP (in permanent international dollars of 2011) for 1988 to 2018. The forecast for 2010 using the data of 1990-2008 under the linear regression. Illustration of the failure of continuous forecasting models

Source: own evaluation. 
On the basis of 1990-2008 data the forecast for 2010 was carried out. According to the linear regression equation, the GDP for 2010 is $\mathrm{Y}=-23.281 * 2010+53180=6385$, while real GDP was 7824; deviation of -1438 or $18.3 \%$ of the predicted value (Figure $2 \mathrm{a}$ ). It is illustration of the failure of continuous forecasting models.

The polynomial regression of the 2nd order seemed to describe the basic observations better, but the prognosis differs from the real result by $60 \%$ (Figure $2 \mathrm{~b}$ ).

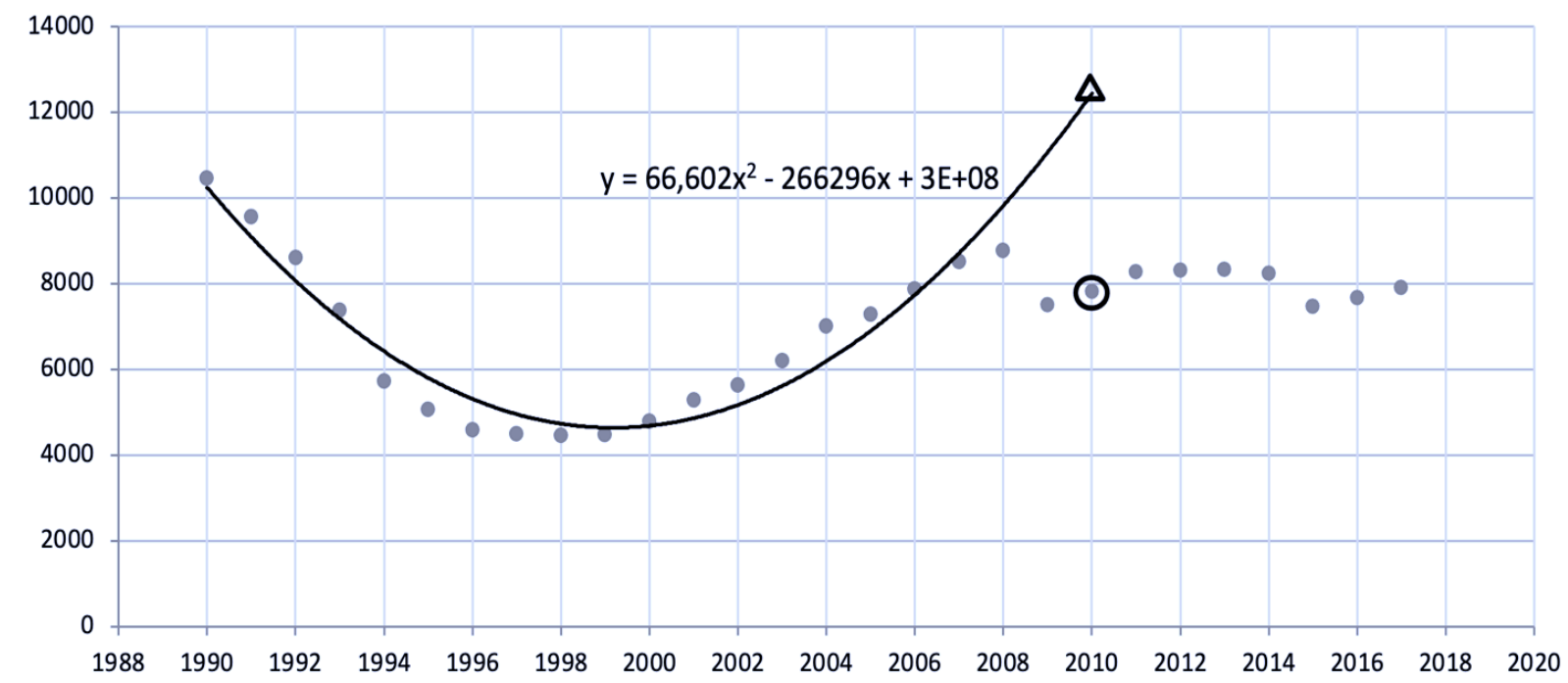

Figure 2b. Ukraine. The GDP performance per capita at the PPP (in permanent international dollars of 2011) for 1988 to 2018. The forecast for 2010 using the data of 1990-2008 under the polynomial regression.

Source: own evaluation.

For comparison, Figure 3 shows the results of a similar experiment for the Czech Republic.

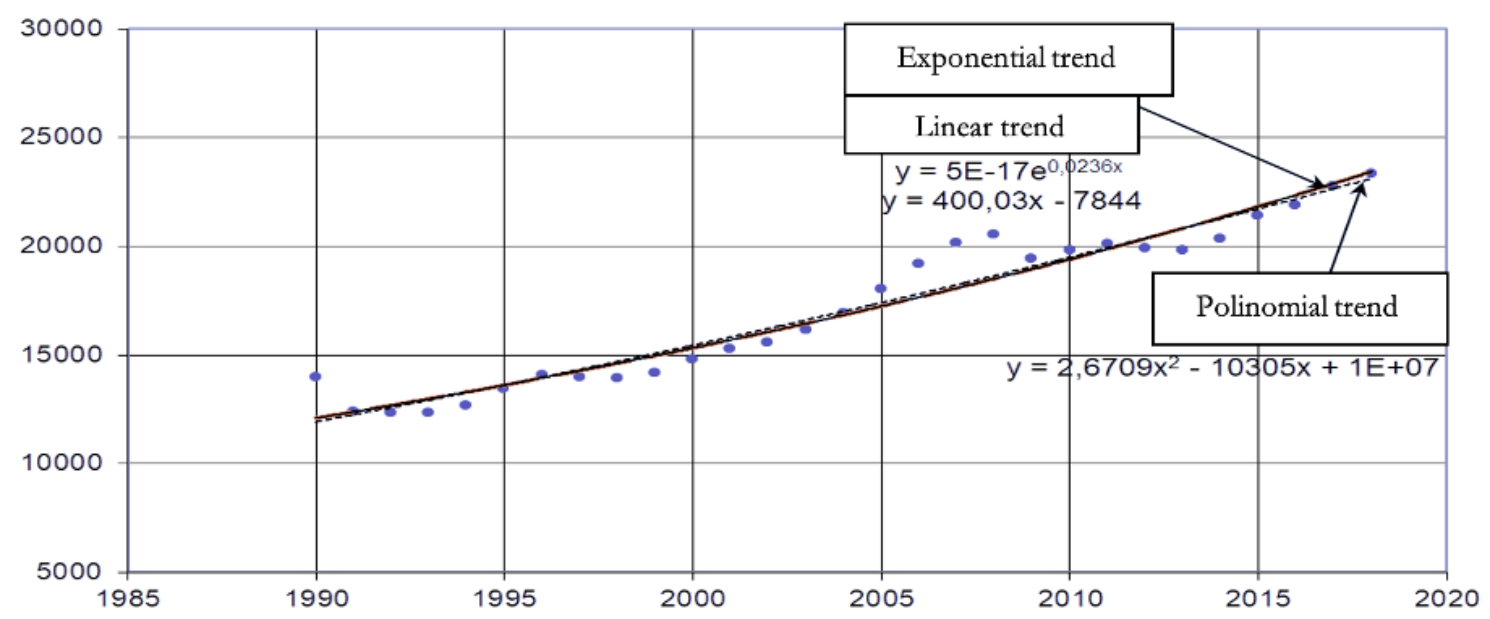

Figure 3. The Czech Republic. The GDP performance per capita at the PPP (in permanent international dollars of 2011) for the period from 1990 to 2018.

Source: own evaluation 
As is evident from Figure 3, the linear, polynomial and exponential models (for the Czech Republic) are observationally equivalent. At the same time, they describe the trend much more accurately than similar data for Ukraine. The GDP performance in 2018 amounted to $192 \%$ of the 1992 value with the growth of $+92 \%$.

The same experiment was conducted for Poland and for Slovakia with the similar outcome. The correlation coefficient amounted to 0.992 (Poland), once again proving high efficiency of the conventional continuous model for the steadily developing economies. The Poland GDP performance in 2018 amounted to $279 \%$ of the 1990 value with the growth of $+179 \%$.

Figure 4 shows the result of the experiment on the use of continuous trends for forecasting on the example of a stable economy (the Czech Republic). The base is the same period: 1990 - 2008. Even the simplest linear trend has been successful, making polynomial regression redundant. Linear regression equation: $\mathrm{Y}=426.82 \mathrm{X}-837951$. The estimated value of GDP for 2010 is 19957 (in Figure 4 it is marked with a triangle). The real value is 19808 . The deviation is +149 or $+0.7 \%$ of the predicted value.

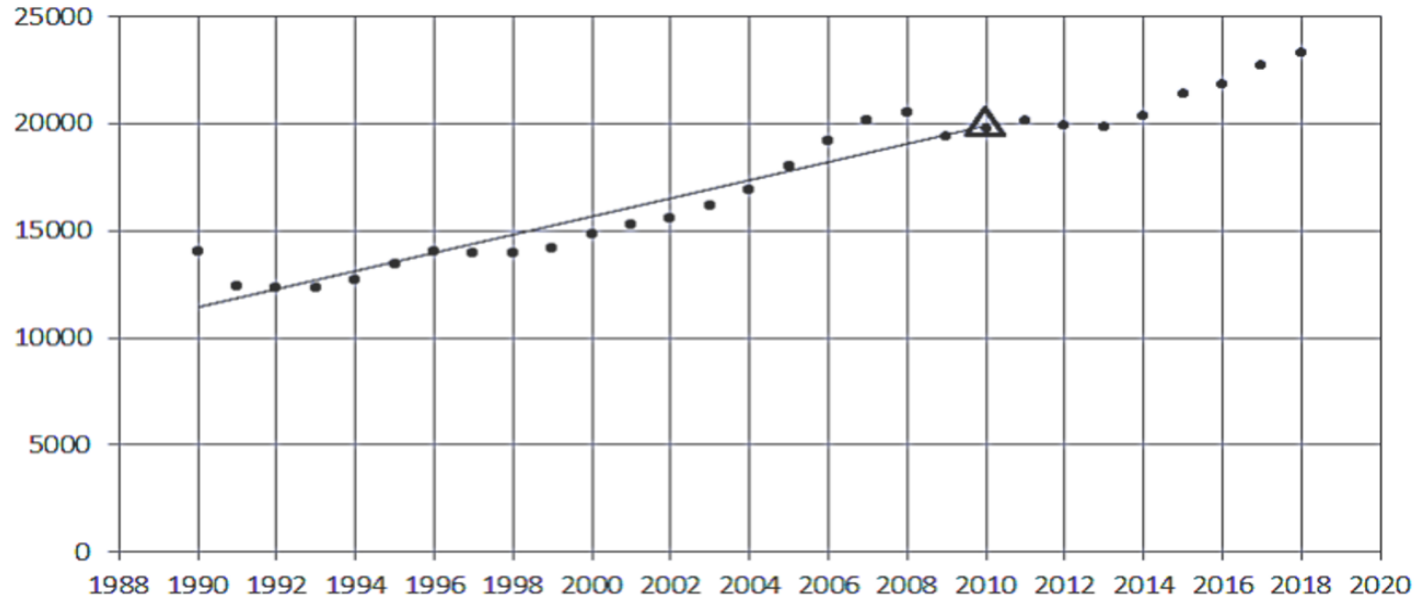

Figure 4. The Czech Republic. The GDP performance per capita at the PPP (in permanent international dollars of 2011) for 2010, according to the equation of linear regression, calculated using the baseline of $1988-2008$.

Source: own evaluation

The following describes the proposed algorithm for estimating the parameters of the proposed model using a piecewise linear function based on the results of observations. The equation describing the dependence of the indicator on time $t$ has the form:

$$
y_{i}=f\left(x_{i}, a_{1}, a_{2}, \ldots, a_{k}\right)+\Delta_{i}
$$

where $a_{1}, a_{2}, \ldots, a_{\mathrm{k}}$ are the regression parameters; $\Delta$ - random deviation from the regression (trend); $i$ - number of observations.

The task is to estimate the parameters of the regression (trend) from observations $\left(t_{i}, y_{i}\right)$. If parameters are included in the expression of regression linearly or it can be transformed to such form, it is reduced to solving the so-called system of normal equations of the method of small squares. Minimization of the quadratic form leads to it:

$$
S=\sum_{i=1}^{n}\left(y_{i}-f\left(x_{i}, a_{1}, a_{2}, \ldots, a_{k}\right)\right)^{2}
$$

The trend, in the expression of which the parameters enter linearly, should have the form: 


$$
f\left(x, a_{1}, a_{2}, \ldots, a_{k}\right)=\sum_{j=1}^{k} a_{j} \varphi_{j}(x) .
$$

The discussed model, however, does not allow reducing the problem to solving a system of normal equations. The reason is the presence of the breakpoints of the regression function among the parameters. We had to develop a computer program that would solve this problem. It was achieved, and this gives reason to claim our involvement in the development of a new method for analyzing the dynamics of economic indicators applicable to the countries where the economic dynamics is of unstable nature. The program was developed in the PTC Mathcad 15.01 environment (developer: PTC, Windows OS).

The idea of algorithm implies minimization of the quadratic form (2) of the method of statistical testing (also known as the Monte Carlo method). It has received growing popularity with the researchers. Since the piecewise linear model was used, the list of parameters is limited to the discontinuity points in the regression function, describing the timing series under study. Then regression between them is a linear function, assessment of coefficients of which is described in any mathematical statistic handbook, and the software implementation is provided by popular software products - such as Excel or Statistica.

The local portion of the regression between the discontinuity points $G_{i}, G_{i+1}$ is described by the equation:

$$
F_{i}\left(x, G_{i}\right)=A_{i} x+B_{i},
$$

where $A_{i}, B_{i}$ are the regression coefficients, calculated as:

$$
\begin{gathered}
A_{i}=\frac{\sum_{\left\{j \mid G_{i} \leq X_{i}<G_{i+1}\right\}}\left(X_{j}-\bar{X}_{i}\right)\left(Y_{j}-\bar{Y}_{i}\right)}{\sum_{\left\{j \mid G_{i} \leq X_{i}<G_{i+1}\left(X_{j}-\bar{X}_{i}\right)^{2}\right.}, \quad B_{i}=\bar{Y}_{i}-A_{i} * \bar{X}_{i},} \\
\bar{Y}_{i}=\frac{\sum_{\left\{j \mid G_{i} \leq X_{i}<G_{i+1}\right\}} Y_{j}}{n_{i}}, \quad \bar{X}_{i}=\frac{\sum_{\left\{j \mid G_{i} \leq X_{i}<G_{i+1} X_{j}\right.}}{n_{i}}
\end{gathered}
$$

$Y_{j}$ - the index value at point $X_{j}, n_{i}$ - the number of $X_{i}$ values within the range of $G_{i}, G_{i+1}$.

The $m$-dimensional parallelepiped is formed $P=\left(Q_{k}, T_{k}, k=1 . . m\right),\{Q, T\}$ - the opposite apexes, $m-$ the number of the boundaries assumed between the areas of continuity. Before the beginning of iteration process the initial value of the form (2) is fixed in the variable $S$, which may be taken from one of the apexes $\mathrm{P}$, while the vector $\mathrm{D}$ reflects the very initial approximation. Thereafter, the program shifts to the execution of the generation cycle of random vectors $T_{k}$ in $\mathrm{P}(k=1 . . N)$, where $\mathrm{N}$ is a number of random test cycles. Upon every execution of the cycle, the calculated value of the quadratic form (2) is assigned to variable $S$, if such value is less of the previous value, and the vector $D$ changes its value to the current vector $\mathrm{T}_{\mathrm{k}}$.

After the cycle is completed, the returned information is generated and a graph of the indicator dynamics is displayed against the background of the starting points of observations $\left(t_{j}, y_{j}\right)$.

A sample output of the graph is shown in Figure 5. 


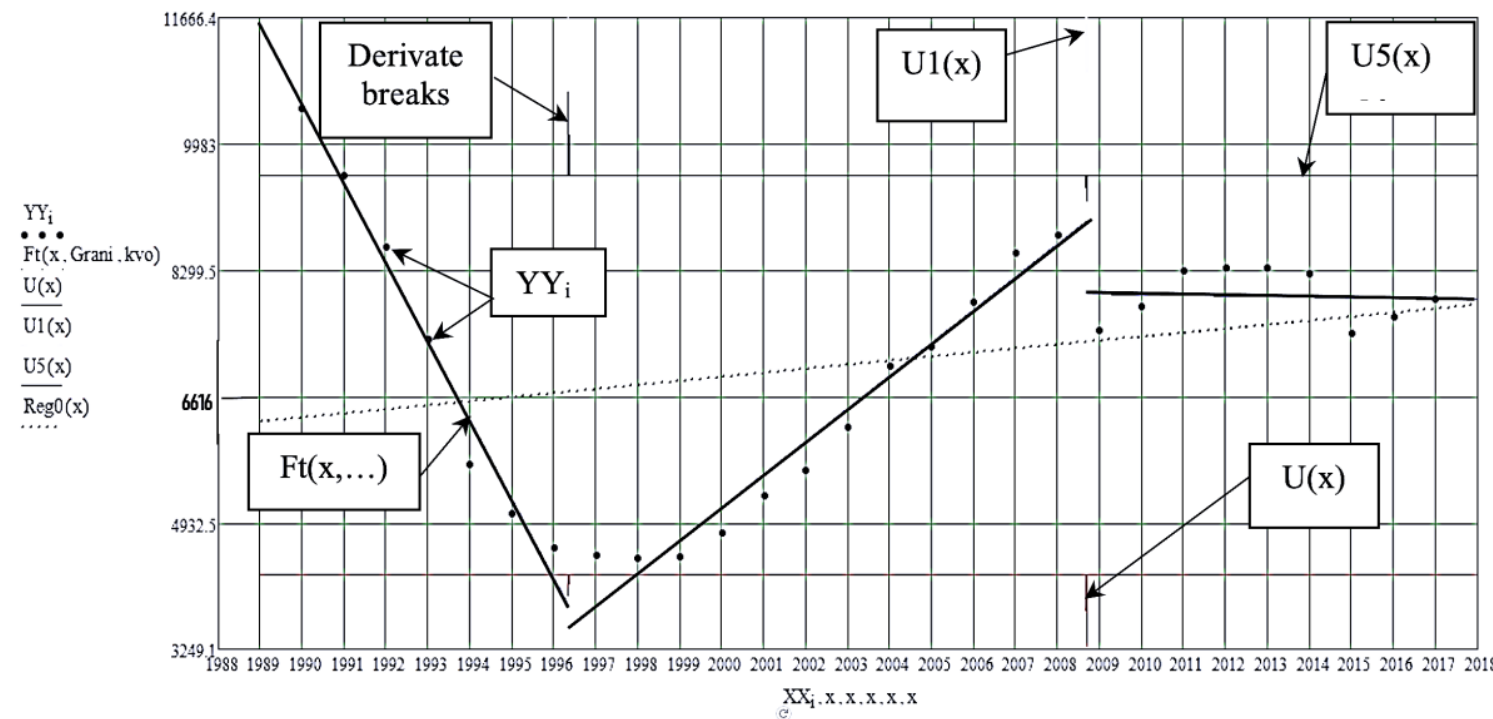

Figure 5. Example of the return results. Ukraine. The number of the areas of continuity $(\mathrm{NAC}=3) ; Y_{\mathrm{i}}$ - observation; Ft(x, ...) - the regression function; $\mathrm{U}(\mathrm{x}), \mathrm{U1}(\mathrm{x})$ - gap amplitudes; U5(x) - showing the gap of the regression's derived function (up - positive, down - negative; height (deepness) of the «peaks» is proportional to the derivative gap amplitude).

Source: own evaluation

Initial data:

- the xls-file with a table of the indicator observations by year; data gaps are allowed, since the program automatically excludes such observations from processing;

- the set number of random test generation cycles $\mathrm{N}$;

- the number of areas of continuity (NAC) for the subsequent assessment of their optimal number;

- the parameters defining program execution modes, the purpose of which is clear from its explanations.

For a comparative analysis, the following indices are provided:

- the index VS of the discrepancy between the data and the model, calculated as the ratio of the estimate of the mean square deviation of the observations (RMS) of the indicator to the RMS of the observations themselves throughout the sample; the range of values it takes is [0;1];

- correlation relation $\varrho$, characterizing the degree of observational compliance with the obtained estimate of the regression function;

- GII growth instability index (the average of the modules of deviations of the indicator from linear regression over the entire area at break points to the magnitude of the mentioned regression on the observation area).

The latter is calculated in the form of (Figure 6):

$$
G I I=\frac{\sum_{i=1}^{K} D_{i}}{K \cdot D}
$$

where $D_{i}$ - the module of deviation between the piecewise continuous regression and the linear regression at $i$-th discontinuity point, $K$ - the discontinuity point number, $D$ - the range of linear regression over the entire observation area. The interpretation of this index is obvious: for the unsustainable economies it increases, while for the stable ones it decreases. 


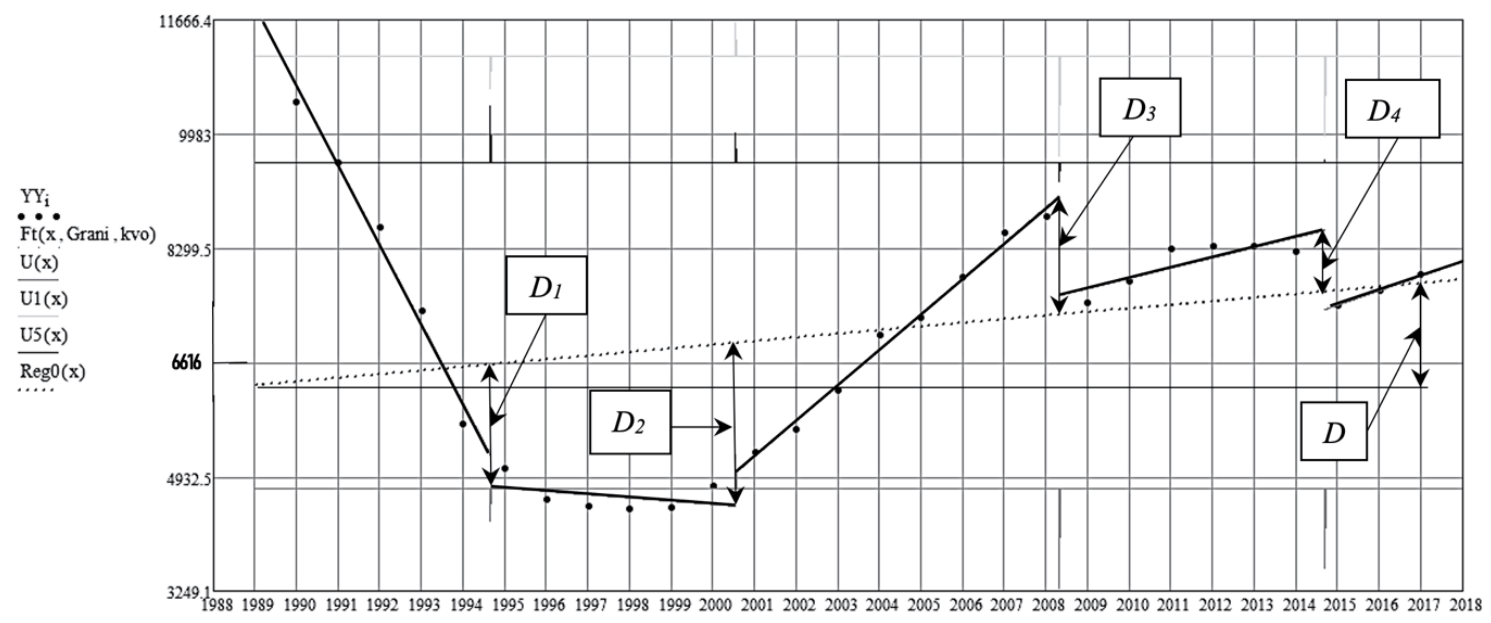

Figure 6. Determination of the growth instability index.

Source: own evaluation

The indices VS and $\varrho$ take values in the range of 0 .. 1. The higher is $\varrho$, the higher is the degree of conformity; the decrease of VS speaks for the same. In the event of ideal conformity, $\varrho=1$, VS $=0$. With a complete discrepancy - when the regression is a constant equal to the average value $-\varrho=0$, VS $=1$. There is an option of the interactive mode; the interpretation causes no difficulties.

After obtaining the results with successive NAC values, preliminary results are evaluated. If it is necessary to clarify the obtained evaluations or making sure their sustainability thereof, processing is repeated with the increased values of $\mathrm{N}$. At the same time, the number of tests is estimated, which ensures the stability of the estimates. In the course of the research, the values of $\mathrm{N}$ ranged from 2000 to 10000.

Upon completion of processing with successive values of NAC, using the standard tools of MS Office, the chart of VS and $\varrho$ dependence on NAC is formed. The optimal assessment for the number of the areas of continuity, along with the dynamics, optimal modes are determined using the stabilization feature of this connection, with the $\varrho$ lever being 0.99 or higher, or the VS at the level of 0.1 or lower.

\section{EMPIRICAL RESULTS AND DISCUSSION}

The prospects of the method are demonstrated by the following results of its application in Ukraine, where instability phenomena are manifested with a textbook persuasiveness. For comparison, a similar study was conducted for the Czech Republic, Slovakia and Poland.

Below the experiment description is given.

Three Excel documents contain summary of the actual data for the period from 1989 to 2018 in terms of the GDP dynamics per capita at the PPP for Ukraine, the Czech Republic, Poland and Slovakia. The data was obtained from the (World Bank, 2019). At NAC=1 the chart of Ukraine's GDP dynamics per capita at the PPP for 1990 to 2017, as built by the program, repeated the chart earlier shown on Figure 1a, i.e., the common linear regression. The obtained estimation of the model data conformity is disappointing: $\varrho=0,261$, VS $=0,965$. The model is unacceptable for Ukraine. At the very first step of the suggested method application (at NAC=2) for Ukraine related data the advantage of the piecewise linear model over the continuous model became evident (Figure 7). 


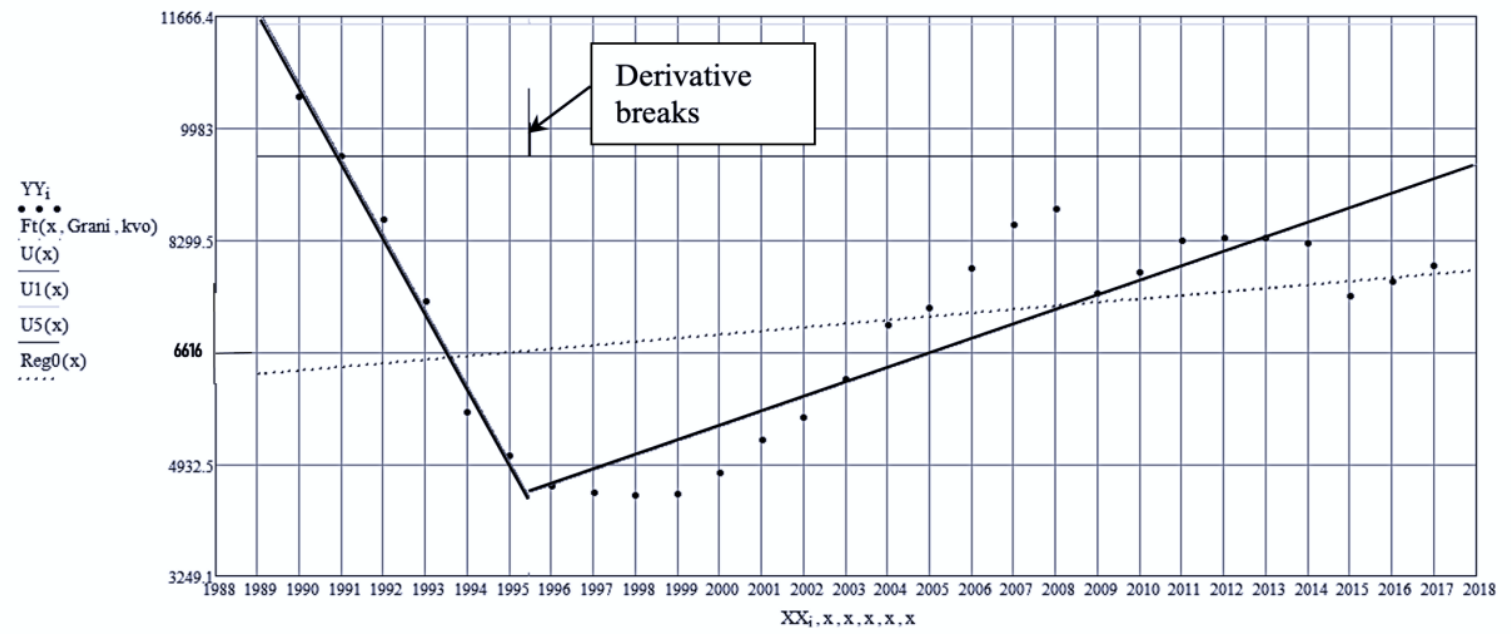

Figure 7. Ukraine, the GDP dynamics per capita at the PPP for 1990 to 2017, NAC=2.

Correlation ratio $\varrho=0,899$, VS $=0,437$.

Source: own evaluation

The $\varrho$ value raised from the extremely low to rather reliable one, equaling 0.899. Respectively, the VS decreased from 0.97 to 0.437 . The established boundary between the areas of continuity falls on 1994, which is logically well explained by economic reasons. The radical reforms and transformations were launched in Ukraine much later after it acquired independence in 1991. As late as in 1994 the catastrophic decline of economy was halted. The same goes for the GDP stable decline up to 1994: so were the aftereffects of the disintegration of the Soviet Union, establishment of the independent state, the market transformations and ill-conceived reforms.

At $\mathrm{NAC}=3$ the correlation ratio increased up to 0.981 , and the VS decreased to 0.194 , which is truly amazing looking back to the $\varrho$ start point (0.26). The program identified the abrupt gap on the dynamics of the indicator in 1994, 2008 and 2014, as well as significant amplitude of the derivative in 2000. In 1997 Ukraine faced strengthening of the presidential authority and reinforced influence on the key financial and industrial groups, in this case resulting in the shift to growth. The brisk decline in 2008 was caused as in other countries by the global financial crisis. The highest correlation ratio $\varrho=0.993$ was found at $\mathrm{NAC}=5$ (Figure 8).

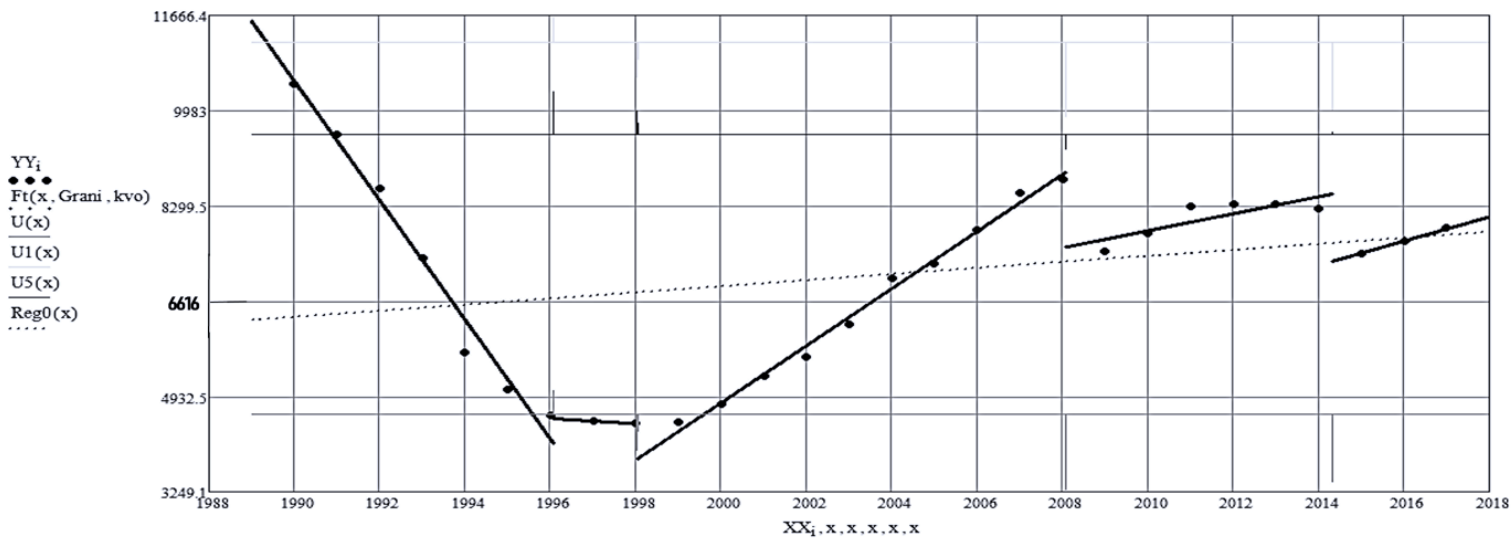

Figure 8. Ukraine. The GDP dynamics per capita at the PPP for 1990 to 2017, NAC=5, $\mathrm{GII}=\mathbf{0 , 8 8 9}$. Correlation ratio $\varrho=0,993$, VS $=0,12$.

Source: own evaluation 
There are 5 periods distinguished in Ukraine's dynamics:

- 1990 - 1998 - the fall of the economy,

- 1996-1998 - a turning point, minimum values of GDP per capita.

- The reforms carried out at that period began to produce results.

- 1998 - 2008 - positive dynamics, stable growth, interrupted by the global economic crisis;

- 2008 - 2014 - uneven growth at a slow pace caused by the consequences of the global crisis. In 2014, the gap in the derivative and, accordingly, a sharp drop in well-being of the population is associated with a period of a change of power in Ukraine, the events on Maidan, the loss of territories and a part of the economic potential;

- 2014 - 2017 - a sharp drop in GDP, the economy was "thrown back", but partially stabilized. Due to external loans, growth was observed.

For Slovakia, the Czech Republic and Poland, developing in a much more stable way, the method, nevertheless, proved to be useful as well, since it managed to clarify the specifics of dynamics (Figure 9, 10, 11, respectively).

For instance, for Slovakia there were three areas outlined being ideally described by the trend, split up in 2003 and the aforementioned 2008, featuring material decline in 2008 (Figure 9).

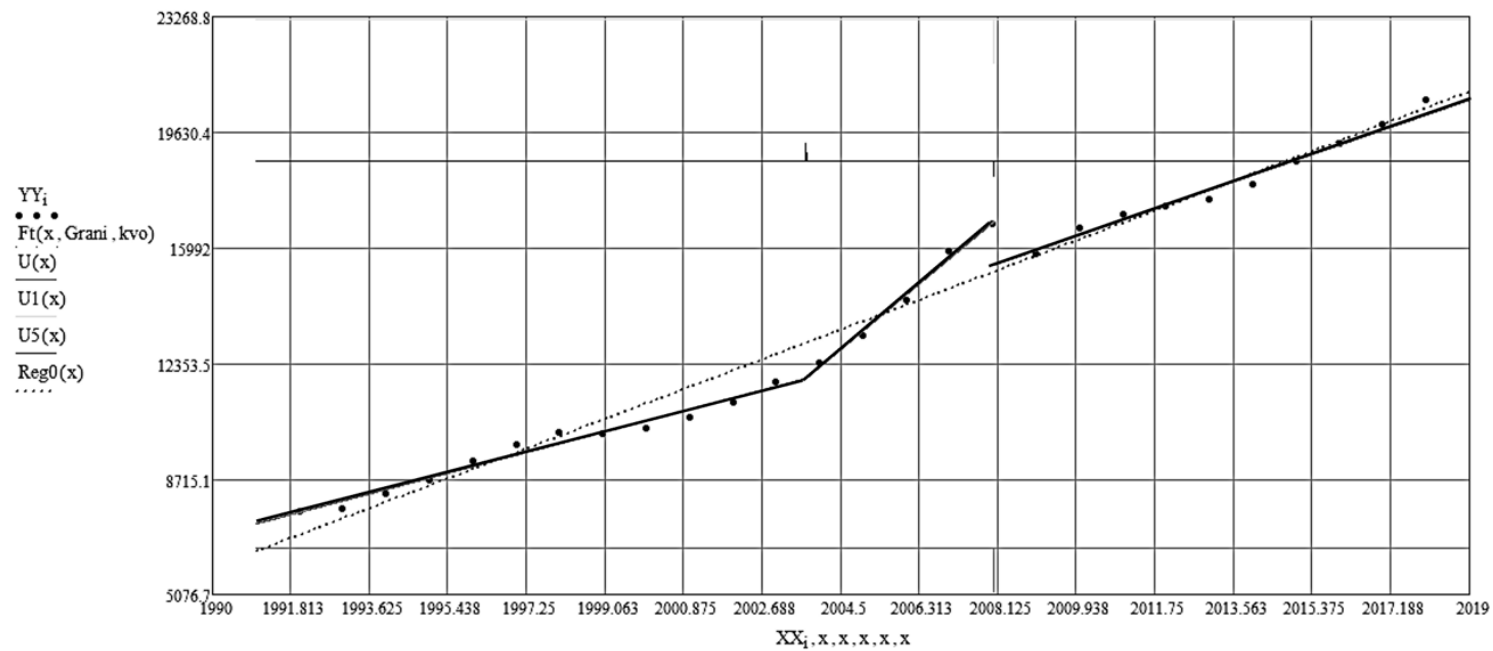

Figure 9. Slovakia. The GDP dynamics per capita at the PPP for 1990 to 2017, NAC=3, GII=0,073. Correlation ratio $\varrho=0,999$, VS $=0,053$.

Source: own evaluation

In general, the nature of trend remained the same, only its velocity changed:

- 1990 - mid 2003 - moderate stable growth;

- 2003 - 2008 - accelerated growth, evidently induced by preparation for joining the EU;

- 2008 - 2018 - moderate growth, but the rate is higher than during the first period. The discontinuity of 2008 is also caused by the global crisis, although its impact being much weaker than that on Ukraine's economy.

The dynamics of the Czech Republic is also well described by the suggested model (Figure 10). 


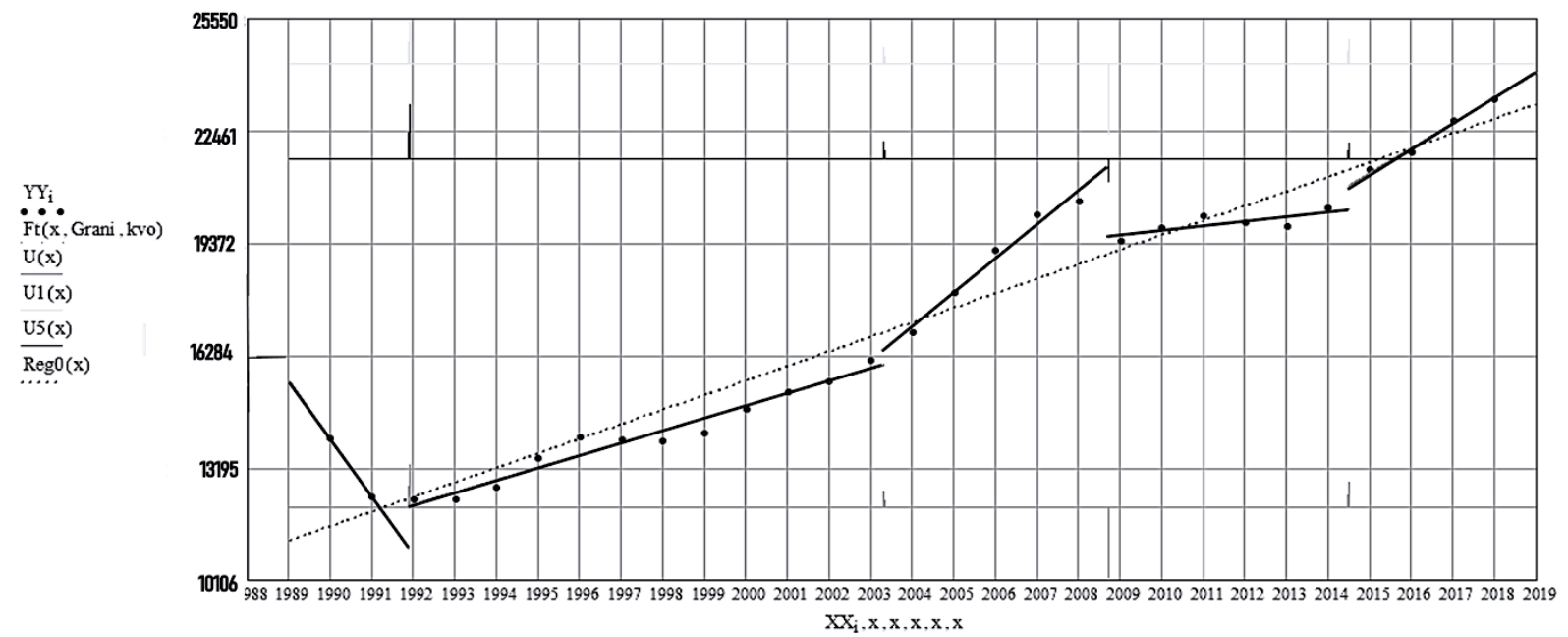

Figure 10. The Czech Republic. The GDP dynamics per capita at the PPP for 1990 to 2017, $\mathrm{NAC}=5, \mathrm{GII}=0,106$. Correlation ratio $\varrho=0,998, \mathrm{VS}=0,064$.

Source: own evaluation

The 1992, 2003 and the aforementioned 2008 do stand out. During this period the trend is changing, like that in Slovakia:

- before 1991 - decline;

- 1992 - 2003 - generally moderate, not completely uniform growth;

- 2003 - 2008 - accelerated growth;

- since 2008 - 2014 moderate, unstable growth, the rate is higher than in 1991 - 2001, but lower than during the preceding period;

- since 2014 - accelerated growth.

The GDP dynamics in Poland constitutes practically an ideal uniform trend. Even for the continuous model at $\mathrm{NAC}=1$ the correlation ratio $\varrho$ was 0.992 , and the VS index of the data discrepancy with the model VS was low (0.126). Nevertheless, the dynamics description using this model at NAC=4 seems to be more detailed (Figure 11).

The years of 1991, 2006 and 2015 stand out in the chart of Poland. The derivative gaps fall on the following years (Figure 11):

- before 1991 - decline;

- 1991 - 2006 - stable growth triggered by the vigorous economic reforms launched in 1989 (the "shock therapy"), although unpopular among people. No doubt, half of the foreign debt written off in 1991 became an additional impulse;

- 2006 - 2012 - the brisk positive change in the dynamics, retaining the growth rate at the previous level (Figure 11). It is worth mentioning that the 2008 crisis, although having largely affected not only Ukraine but also the Czech Republic and Slovakia, which are much more stable, in no way influenced the economic dynamics of Poland. Perhaps it is connected with the preparation of UEFA Euro 2012 and the privatization of state shares in almost 300 Polish companies;

- since 2012 - accelerated growth, its rate being somewhat higher than that of the preceding period. No continuous model is able to show it. 


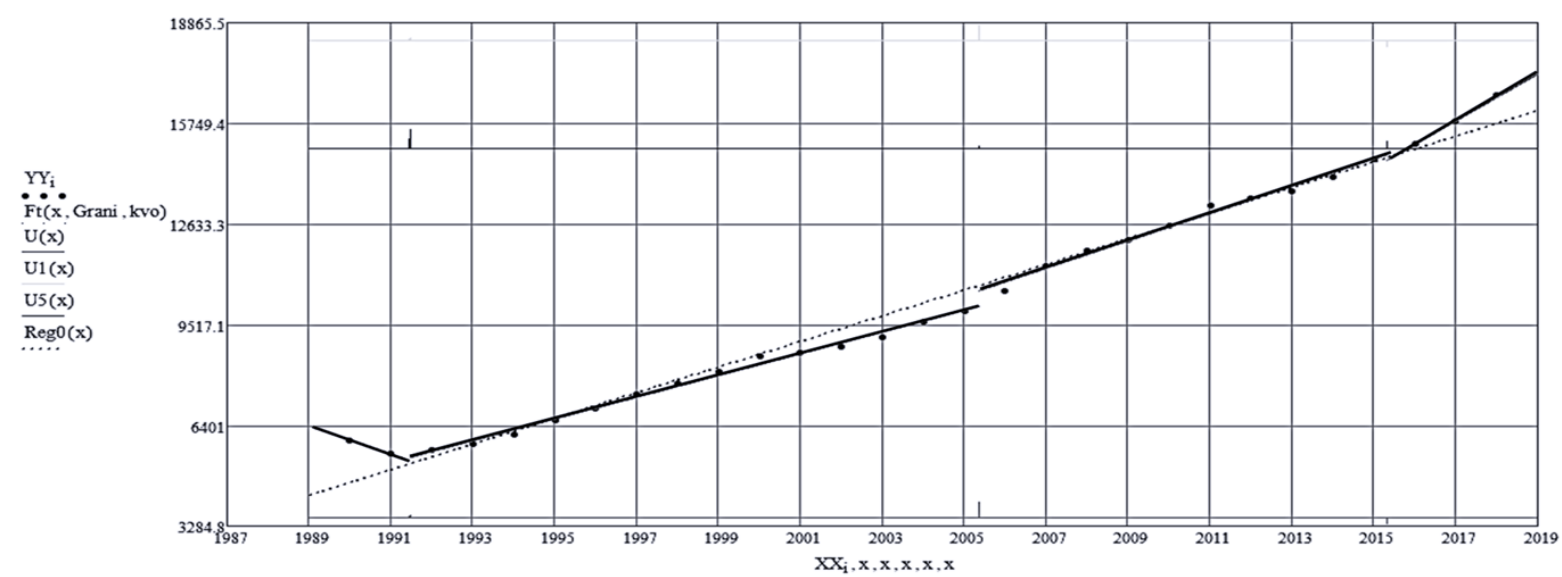

Figure 11. Poland, the GDP dynamics per capita at the PPP for 1990 to 2017, NAC=4, GII=0,03. Correlation ratio $\varrho=0,9993$, VS $=0,038$.

Source: own evaluation

The positive economic dynamics of Poland over such a long period seems to be connected, firstly, with the consistency and continuity of reforms and low levels of corruption, and, secondly, Poland's participation in many EU financial programs. Moreover, according to experts from the World Bank, the IMF and European institutions themselves, Poland turned out to be one of the most conscientious recipients of loans and financial assistance.

This seems to be the main reason for the effectiveness of Polish reforms. For example, despite significant financial support from the EU since 2010, Greece defaulted in 2015. Ukraine also cooperated with the IMF in 1994 - 2002 and from 2008 to the present time. Of course, loans are a saving and stimulating factor for the Ukrainian economy. However, it is impossible to overcome the instability of the economy only at their expense, without pursuing an appropriate domestic policy (Teichmann et al., 2020).

Important note. The program establishes the optimal position of the points of discontinuity, even if the amplitude of the dynamics in them is microscopic. And when at such a point a sudden change in the nature of continuous development occurred without breaking the dynamics itself, for example, weakening or strengthening of growth rates, as was observed in the Czech Republic and Slovakia in 2008 (Figure 9, 10), or in Poland in the second half of 2012 (Figure 11), the derivative is subjected to discontinuity, and the program reacts thereto. No conventional method is able to identify this peculiarity. To estimate the optimal number of NAC uniform areas, it is offered to build a dependence of the regression data conformity on the assumed number of areas. Figure 12 shows such charts for Ukraine. Both indicate that upon first approximation, growth of both indices stabilized at NAC $=3$ ( $\varrho=0,981$, VS $=0,194)$, and the peculiarities in further details were modeled at NAC $=5$.

The left part of Figure 12 shows the correlation ratio $\varrho$, and the right one - the VS index of the model data inconformity. The NAC is estimated using the natural criterion of the conformity index stabilization at certain NAC value. The following estimations are pointed out in Figure $12-\mathrm{NAC}=2$, $\mathrm{NAC}=3$ and $\mathrm{NAC}=5$. The differences between this and the previous value automatically range these values. Thus, at NAC $=21996$ conforms to the most significant discontinuity (it would be appropriate to use the "turbulent 90s" term). That was the long period of the economy decline in Ukraine being halted. The second ranking goes for $\mathrm{NAC}=3$ with noticeable hike of $\varrho$ from 0,899 to 0,981 . The $\varrho$ level from 0,99 and higher for every experimentalist, either a physician, medical doctor or economist means an absolute success in selecting a model. In this case, the growth of $\varrho$ is terminated at NAC $=5$. The same 
conclusions are supported by the VS (Figure 12), which dropped twice when shifting from NAC $=2$ to $\mathrm{NAC}=3$ and got stable at NAC $=5$.
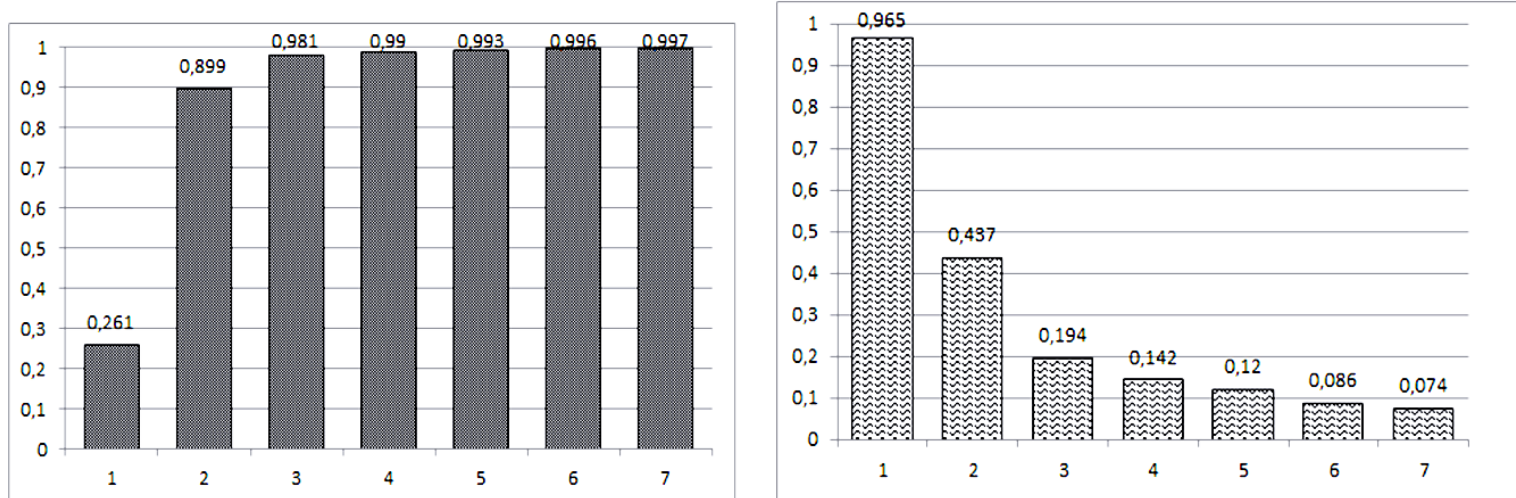

Figure 12. Ukraine chart of the correlation ratio @ dependence and the VS index on the number of the areas of continuity NAC.

Source: own evaluation

As the above results show, the proposed method provides new opportunities for analysis of the manifestations of the instability of the dynamics of macroeconomic indicators. Its high efficiency is confirmed by uniquely high values of the correlation ratio - by the level of 0.99 and even higher. Model adequacy based on data from sustainable developing countries proves its versatility.

To test the conclusion about the universality of the model, we used the data of the World Bank on the dynamics of GDP per capita (World Bank, 2019) of several countries considered in the literature as experiencing macroeconomic fluctuations: Italy and Greece. As seen from Figure 13 (Italy) and Figure 14 (Greece), the proposed model shows a high level of compliance and, in general, confirms the conclusion about its effectiveness.

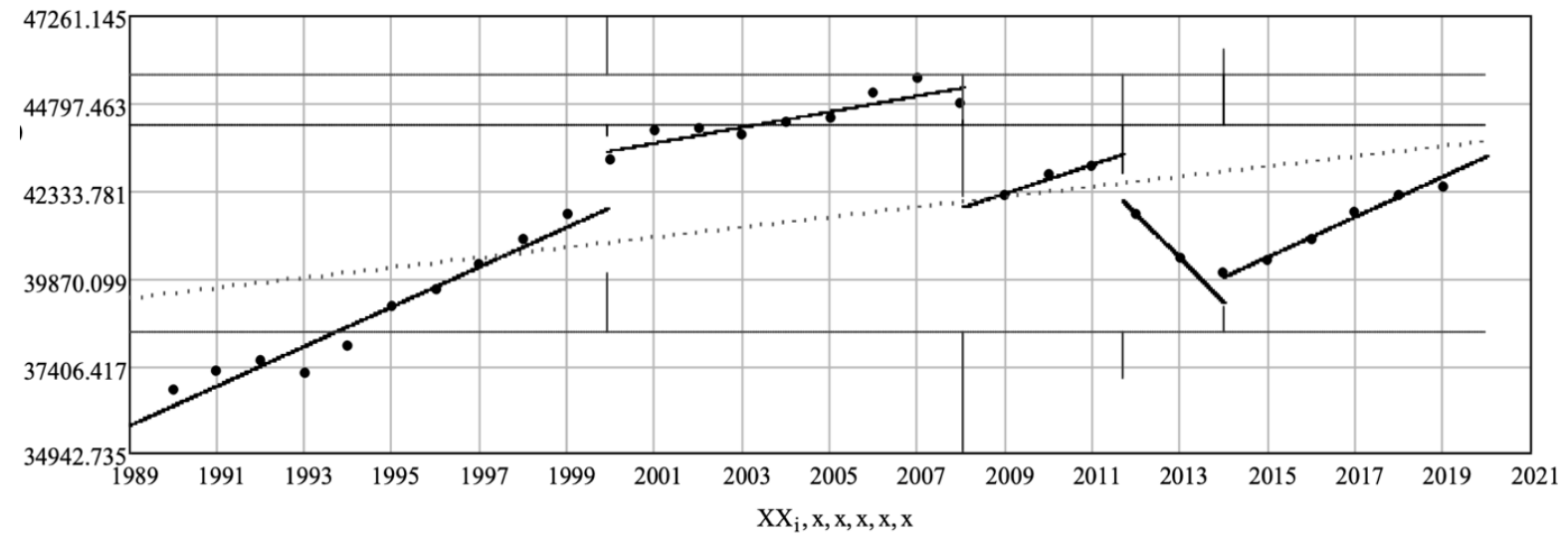

Figure 13. Italy. Dynamics of GDP per capita in PPP for the period 1989 - 2019, NAC = 5, $\mathrm{GII}=\mathbf{0 , 6 2 4}$. Correlation ratio $\varrho=0,9864$, VS $=0,164$.

Source: own evaluation

Figure 13 shows the simulation results from Italy data. Changes in periods of growth and decline are clearly established:

- 1989 - 1999 - moderate economic growth rates, which slowed down in 2000 - 2008.

- After the global crisis of 2008, in 2009 there is a local decline in GDP per capita, but the trend of insignificant growth persists for the next 2 years. 
- $\quad$ From 2012 to 2014, there is a decline, which is subsequently replaced by growth. The Italian economy's vulnerability and volatility is associated with high public debt, low productivity and competitiveness.

- $\quad$ Figure 14 shows data on the dynamics of GDP per capita in Greece.

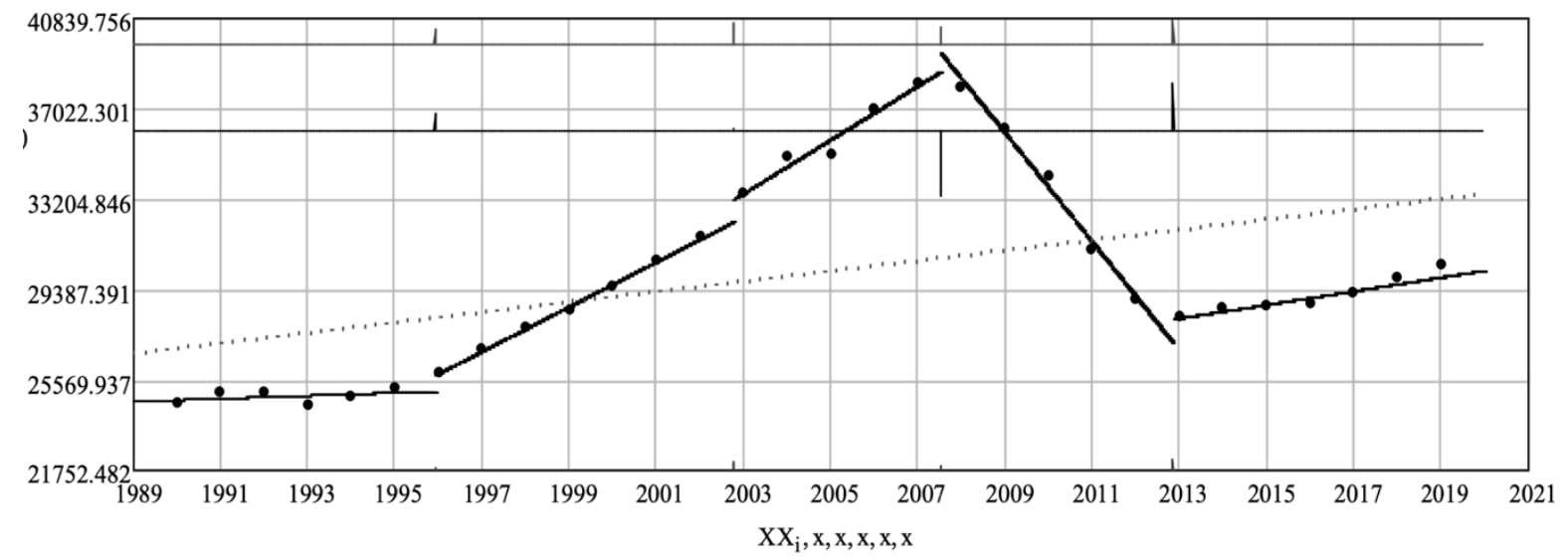

Figure 14. Greece. Dynamics of GDP per capita in PPP for the period 1989 - 2019, NAC = 5, $\mathrm{GII}=\mathbf{0 , 6 9 3}$. Correlation ratio $\varrho=0,9959, \mathrm{VS}=0,09$.

Source: own evaluation

The intervals of continuity are clearly traced:

- 1989 - 1995 - practically zero rates of economic growth caused by the current and previous irrational economic policies and deformations: a significant share of the public sector, a high role of the state in the economy, historically accumulated debt and its further growth, irrational social policy, a high share of loans, low exports, monopolization and low competitiveness of the economy.

- 1996 - 2002 - economic growth, the pace of which is increasing in 2003 - 2008, which is associated with the entry of Greece into the European Monetary Union and the receipt of appropriate assistance from European funds. However, the economic policy actually opposes foreign investment, the budget deficit and the deficit of the foreign trade balance are growing.

- 2008 - 2012 - decline caused by the global financial crisis, debt crisis, significant trade deficit, low labor productivity, low investment activity; increasing unemployment, inflation and poverty. This has become an international problem (Bird at al., 2017).

- 2012 - 2019 - overcoming the crisis and growing at a moderate pace.

The authors built a rating of 43 European countries according to the growth instability index (GII) (Figure 15). Liechtenstein, Monaco and Andorra are excluded due to lack of data.

The rating is topped by Ukraine with an extremely high GII $=0.889$

The group of countries with high GII values (0.624 - 0.693) are Italy, San Marino, Greece. The presence of Italy and Greece is explained by the instability of growth during the period under review, and San Marino is due to the direct dependence of the economy on the surrounding Italy. The distance between Ukraine and European countries is very impressive. This is explained by the fact that there is an important destabilizing factor in Ukraine, which is absent in Europe - a permanent military conflict. It seems that this is not the only reason (Teichmann at al., 2020).

Countries with a GII value below the average - from 0.2 to 0.3 , which is $2.5-3$ times less than the previous group. The group includes Portugal, Croatia, Finland, Spain, Belarus, the Russian Federation. 
A significant part of European countries (22) belong to the group with a low growth volatility index: from 0.1 to 0.2. This includes almost all the countries of northern Europe, Great Britain, small and large EU countries and Kazakhstan.

Countries of stable growth: the index is less than 0.1 - Bosnia, Germany, Serbia, Macedonia, Moldova, Lithuania, Kosovo, Malta, Slovakia, Albania and Poland.

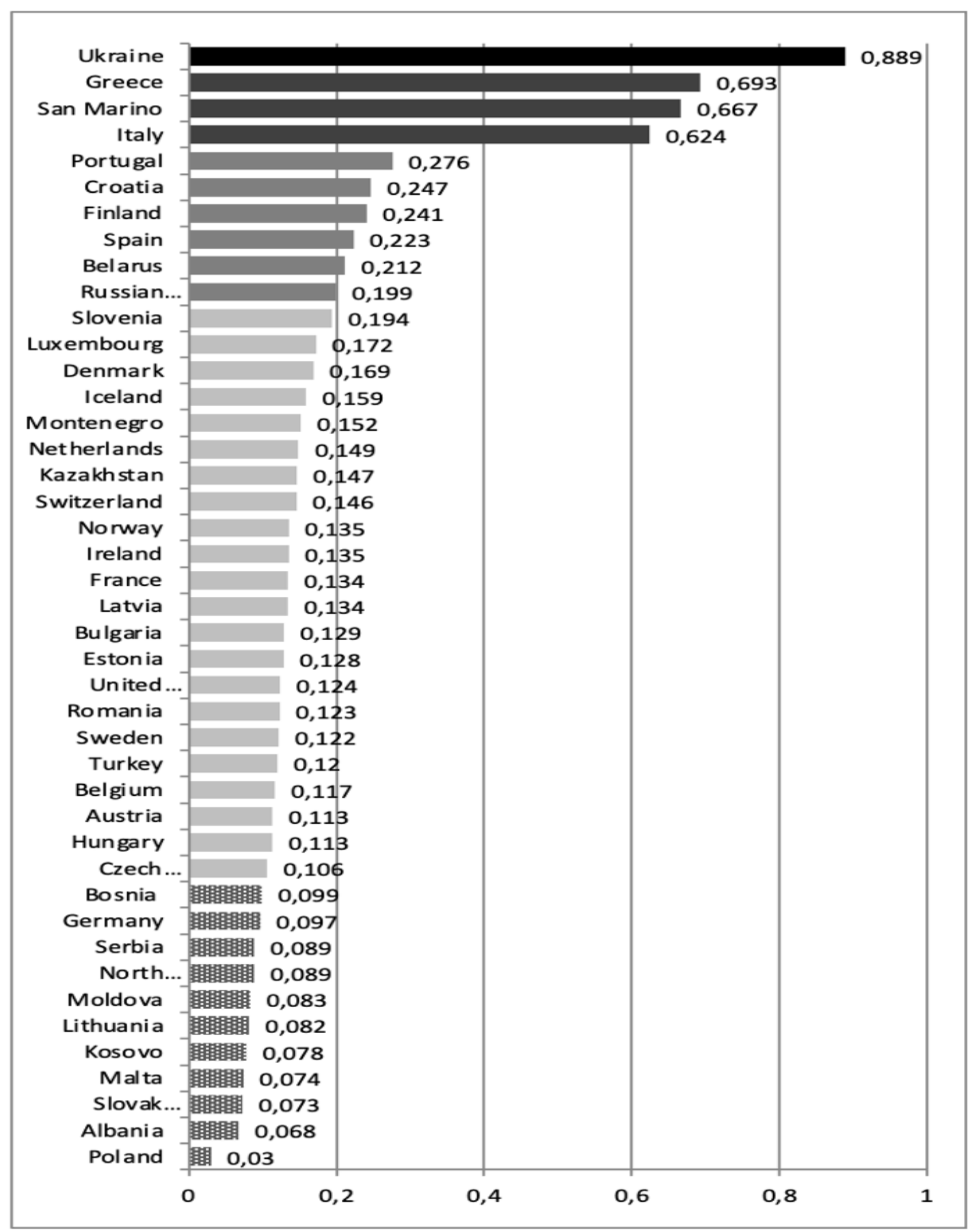

Figure 15. Rating of European countries in terms of GII

Source: own evaluation 
The authors conducted a statistical analysis, during which they estimated the correlation coefficients between the GII value and indices and individual indicators that could indicate factors of growth instability:

- the group of indicators of the quality of public administration (Worldwide Govermance Indicators, 2019), includes 6 indices: Voice and Accountability; Political Stability and Absence of Violence; Government Effectiveness; Regulatory Quality, Rule of Law; Control of Corruption.

- Social Progress Index (The Social Progress Imperative, 2019), which takes into account over 50 indicators;

- the index of the effectiveness of national education systems (Global Index of Cognitive Skills and Educational Attainment, 2016);

- Global Innovation Index (Global Innovation Index, 2019);

- Global Competitiveness Index (The Global Competitiveness Report, 2019).

- unemployment rate, \% of labor force (World Bank, 2019).

- share of exports in GDP, \% (World Bank, 2019);

- share of imports in GDP, \% (World Bank, 2019);

- the share of public debt in GDP, \% (World Bank, 2019);

- the share of foreign direct investment in GDP, \% (World Bank, 2019).

The correlation coefficients turned out to be statistically insignificant, in the range of $-0.3 \ldots 0.4$. The absence of statistically significant relationships means that the proposed indicator GII has its own independent meaning. It does not have already known indices as its origin.

\section{CONCLUSION}

The results presented in the article showed a high degree of adequacy of the proposed model of the piecewise-linear trend to the statistical data on the dynamics of GDP per capita in European countries (the correlation ratio is within 0.9864 .. 0.999). The constructed rating of European countries according to the value of the GII index proposed by the authors is consistent with the conclusions of the IMF regarding countries with the most pronounced manifestations of instability (Ukraine, Greece, Italy). The proposed model opens up new opportunities for analyzing economic growth in stably growing economies, establishing the moments of change in the rate of economic growth and its nature, the duration of growth periods. The parameters of the model, in contrast to those previously used, have a natural economic content. The authors see the prospects for the development of the method primarily in the direction of a similar multidimensional model.

\section{ACKNOWLEDGEMENT}

Not applicable. 


\section{REFERENCES}

Baburin, V.L. (2019). The resistance of the greater Baltic region states to market cycle changes, Baltic Region, 11(1), 413. doi:10.5922/2079-8555-2019-1-1.

Baltas, N., Tsionas, M., \& Baltas, K. (2018) Foreign direct investment in OECD countries: a special focus in the case of Greece. Applied Economics, 50(52), 5579-5591. doi: 10.1080/00036846.2018.1488054.

Basciftci, B., Ahmed, S., Shen, S. (2021). Distributionally robust facility location problem under decision-dependent stochastic demand. European Journal of Operational Research, 292(2), 548-561. https://doi.org/10.1016/j.ejor.2020.11.002.

Berg, A., \& Ostry, J.D. (2011). Inequality and Unsustainable Growth: Two Sides of the Same Coin? IMF staff discussion note, 11/08. Retrieved from: https://www.imf.org/en/Publications/Staff-DiscussionNotes/Issues/2016/12/31/Inequality-and-Unsustainable-Growth-Two-Sides-of-the-Same-Coin-24686 (09.04.2021).

Bird, G., Du, W., Pentecost, E., \& Willett, T. (2017) Safe haven or contagion? The disparate effects of Euro-zone crises on non-Euro-zone neighbours. Applied Economics, 49(59), 58955904, doi: $10.1080 / 00036846.2017 .1358445$.

Chletsos, M., \& Roupakias, S. (2020). Education and wage inequality before and during the fiscal crisis: A quantile regression analysis for Greece 2006-2016. Review of Development Economics 24(4), 1333-1364/ https://doi.org/10.1111/rode.12695

Cicceri, G., Inserra, G., \& Limosani, M. (2020). A machine learning approach to forecast economic recessions-an Italian case study. Mathematics, 8(2). https://doi.org/10.3390/math8020241

Coleman, T.F., Levchenkov, D., Li, Y. (2007). Discrete hedging of American-type options using local risk minimization. Journal of Banking and Finance, 31(11), 3398-3419. https://doi.org/10.1016/j.jbankfin.2007.04.020

Eurostat. Retrieved from: https://ec.europa.eu/eurostat/web/main/data/database_(09.04.2021).

Fezzi, C., \& Fanghella, V. (2020). Real-Time Estimation of the Short-Run Impact of COVID-19 on Economic Activity Using Electricity Market Data. Environmental and Resource Economics, 76, 885-900. https://doi.org/10.1007/s10640-020-00467-4.

Gawon Yoon. (2013). Common change-points in long-term UK bond yields, 1870-1914: a piecewise linear trends approach. Applied Economics Letters, 20(13), 1254-1258, doi: 10.1080/13504851.2013.802084

Global Index of Cognitive Skills and Educational Attainment Retrieved from: https://www.pearson.com (09.04.2021).

Göbel, M. \& Araújo, T. (2020). Indicators of economic crises: a data-driven clustering approach. Applied Network Science, 5, 44. https://doi.org/10.1007/s41109-020-00280-4.

Karaçuha, E., Tabatadze, V., Karaçuha, K., Önal, N.Ö., \& Ergün, E. (2020). Deep Assessment Methodology Using Fractional Calculus on Mathematical Modeling and Prediction of Gross Domestic Product per Capita of Countries. Mathematics, 8(4) https://www.mdpi.com/2227-7390/8/4/633.

Karnitis, G., \& Karnitis, E. (2017). Sustainable growth of EU economies and Baltic context: Characteristics and modelling. Journal of International Studies, 10(1), 209-224. doi:10.14254/2071-8330.2017/10-1/15.

Kasianova, N., Kendiukhov, O., Kochubei, O., Oliinyk, Y., Sokhatska, O., \& Zhukova, Y. (2020). Digital transformation as an attractor of Ukraine's economic development. International Journal of Advanced Research in Engineering and Technology (IJARET), 11(7), 340-349.

Korotayev, A.V., Bilyuga, S.E., \& Shishkina, A.R. (2020). Which countries generate Kondratieff waves in global GDP growth rate dynamics in the contemporary world? Journal of Globalization Studies, 11(1), 33-63 doi: 10.30884/jogs/2020.01.03.

Kowalski, T., \& Shachmurov, Y. (2018). Economic Development in Poland and Ukraine: The Case of Foreign Trade. Interdisciplinary Journal of Economics and Business Law, 7(2), 35-61. https://www.researchgate.net/publication/321796744 Economic Development in Poland and Ukraine The Case of Foreign Trade. 
Laskowska, I., \& Dańska-Borsiak, B. (2017). The Importance of Human Capital for The Economic Development of EU Regions. Comparative Economic Research. Central and Eastern Europe, 19(5), 63-79. https://doi.org/10.1515/cer-2016-0038.

Matsuyama, K., Sushko, I., \& Gardini, L. (2018). A piecewise linear model of credit traps and credit cycles: a complete characterization. Decisions in Economics and Finance, 41, 119-143 https://doi.org/10.1007/s10203018-0220-5.

Reyes Escobar, A.A., \& Rozo Bernal, C. A. (2020). Greek crisis and financial fragility in Minsky's instability hypothesis. Revista Galega De Economía, 29 (1), 1-18. https://doi.org/10.15304/rge.29.1.6609.

Sobolieva-Tereshchenko, O. (2018). The Bank Card Market: a Comparative Analysis of Ukraine and its Neighboring Countries. Comparative Economic Research, 21, 25-44. https://doi.org/10.2478/cer-2018-0025.

Sobolieva-Tereshchenko, O., \& Zhukova, Y. (2020). Stress testing the banking systems: Approach of Ukraine. Journal of Eastern European and Central Asian Research (JEECAR), 7(2), 205-218. https://doi.org/10.15549/jeecar.v7i2.358.

Soukiazis, E., Antunes, M., \& Kostakis, I. (2018). The Greek economy under the twin-deficit pressure: a demand orientated growth approach. International Review of Applied Economics, 32(2), 215-236, doi: $10.1080 / 02692171.2017 .1338678$.

Stjepanović, S. (2018). Relationship between energy consumption and economic growth in 30 countries in Europe. panel EKONOMSKI PREGLED, 69 (1), 43-57.

Tak KuenSiu (2016). A self-exciting threshold jump-diffusion model for option valuation. Mathematics and Economics, 69, 168-193. https://doi.org/10.1016/i.insmatheco.2016.05.008

Teichmann, F., Falker, M.-C., Sergi, B.S. (2020). Extractive industries, corruption and potential solutions. The case of Ukraine. Resources Policy 69, 101844.

The Global Competitiveness Report 2019. Retrieved from: https://www.weforum.org_(09.04.2021).

The Global Innovation Index (GII) 2020. Retrieved from: https://www.globalinnovationindex.org/Home (09.04.2021).

The Social Progress Imperative. Retrieved from: https://www.socialprogress.org (09.04.2021).

UNdata. Retrieved from: http://data.un.org (09.04.2021).

World Bank. Retrieved from: https://databank.worldbank.org/home.aspx (09.04.2021).

Worldwide Govermance Indicators. Retrieved from: https://info.worldbank.org/governance/wgi/Home/Reports (09.04.2021).

Vlasova, K., \& Govorova, N. (2018). Socio-economic situation in Greece 2008 - 2018: Results and prospects. Sovremennaya Evropa, 5, 98-109. http://dx.doi.org/10.15211/soveurope5201898109

Xiaobo, Zhu, Mingguo, Ma, Hong, Yang and Wei, Ge. (2017). Modeling the Spatiotemporal Dynamics of Gross Domestic Product in China Using Extended Temporal Coverage Nighttime Light Data. Remote Sensing, 9, 626. https://doi.org/10.3390/rs9060626

Yi-Chein Chiang, Tung Liang Liao, \& Yu-Ling Liu (2008). Performance and Investments in China from Industrial Perspectives: Evidence from Taiwan Firms. Review of Pacific Basin Financial Markets and Policies, 11 (3), 331-346. https://doi.org/10.1142/S0219091508001374

Zahariev, A., Zveryakov, M., Prodanov, S., Zaharieva, G., Angelov, P., Zarkova, S., \& Petrova, M. (2020). Debt management evaluation through Support Vector Machines: on the example of Italy and Greece. Entrepreneurship and Sustainability Issues, 7(3), 2382-2393. https://doi.org/10.9770/jesi.2020.7.3(61) 